\title{
USO DE SORGO COM BAIXO TEOR EM TANINOS NA ALIMENTAÇÃO DE FRANGOS DE CORTE
}

$\begin{array}{r}\text { SILVA, Janaina Della Torre }{ }^{1} \\ \text { DIAS, Luciana Thie Seki }{ }^{2} \\ \text { MACHADO, CélioRaimundo }{ }^{3} \\ \text { CARVALHO, Maria Regina Barbieri }{ }^{4} \\ \text { RIZZO, Pricila Vetrano }{ }^{5} \\ \hline\end{array}$

Recebido em: 2009-08-04

Aprovado em: 2009-10-16

ISSUE DOI: $10.3738 / 1982.2278 .281$

RESUMO: Objetivou-se avaliar a influência da adição do sorgo com baio teor em taninos em rações para frangos de corte através do desempenho produtivo, do teor lipídico e do rendimento de carcaça e cortes comerciais, aos 42 dias de idade. Foram utilizados 510 pintos machos (Cobb) com 1 dia de idade. As rações experimentais tiveram o sorgo em substituição ao milho nos níveis $0,25,50,75$ e $100 \%$. O desempenho produtivo, a deposição lipídica corporal e o rendimento de carcaça não foram influenciados pelos diferentes tratamentos. Concentrações inferiores para colesterol total plasmático e deposição lipídica na carcaça foram obtidas para o nível $75 \%$. Conclui-se que a inclusão de sorgo com baixo teor em taninos na ração de frangos de corte parece promissora, pois não influencia negativamente nos índices produtivos, além de diminuir a concentração de colesterol total plasmático e proporcionar tendência de menor deposição lipídica na carcaça.

Palavras-chave: Deposição lipídica. Desempenho produtivo. Frango de corte. Rendimento de carcaça. Sorgo

\section{LOW TANNIN SORGHUM UTILIZATION IN BROILERS FEED}

SUMMARY: The objective of this study was to evaluate the effects of low tannin sorghum in broiler performance, carcass lipid deposition and carcass performance. Fifty hundred and ten Cobb male 1-day old chicks were raised up to 42 days of ag. The experimental diets were formulated based on corn and sorghum in substitution to the corn at levels of $0,25,50,75$ and $100 \%$. The broilers had been weighted for productive performance analysis and killed for carcass performance and carcass lipid deposition evaluation. These parameters did not show statistics differences between treatments. The total cholesterol plasm levels and carcass lipid deposition were lower in 75\% substitution treatment than the others. The results of this study have revealed that sorghum low tannin inclusion in broilers diets did not affect the birds performance and decreased the total cholesterol plasm levels and carcass lipid deposition

Keywords: Lipid deposition. Productive performance. Broiler. Carcass performance. Sorghum.

\footnotetext{
${ }^{1}$ Doutoranda do Programa de Zootecnia da Faculdade de Ciências Agrárias e Veterinárias/UNESP, Via de Acesso Prof. Paulo Donato Castellane, s/n, Jaboticabal - SP - Brasil, CEP 14884-900, e-mail: janainadts@hotmail.com

${ }^{2}$ Professora Adjunto do Centro de Ciências Agrárias/UFSCar, Rodovia Anhanguera, km174 CP 153 Araras - SP - Brasil, CEP13600-970, e-mail: sekidias@cca.ufscar.br

${ }^{3}$ Professor Titular do Departamento de Morfologia e Fisiologia da UNESP, Via de Acesso Prof. Paulo Donato Castellane, s/n, Jaboticabal - SP - Brasil, CEP 14884-900, e-mail: cmachado@ fcav.unesp.br

${ }^{4}$ Professora Assistente Doutor do Departamento de Tecnologia da UNESP, Via de Acesso Prof. Paulo Donato Castellane, s/n, Jaboticabal - SP - Brasil, CEP 14884-900, e-mail: mrbcar@ @ fcav.unesp.br

${ }^{5}$ Mestre em Ciência Animal e Pastagens da Escola Superior de Agricultura "Luiz de Queiroz" Av Pádua Dias, 11 CP 09 Piracicaba - SP - Brasil, CEP 13418-900, e-mail: privetrano@yahoo.com.br
} 


\section{INTRODUÇÃO}

A avicultura de corte constitui-se numa atividade de grande importância sócioeconômica no Brasil. Desta maneira, pesquisas vêm sendo conduzidas no sentido de se maximizar a utilização de insumos disponíveis no mercado interno, objetivando a diminuição nos custos de produção, reduzindo o preço final do frango de corte, sem, contudo, afetar a sua qualidade, tornando a sua aquisição cada vez mais acessível à população. Neste contexto, o sorgo apresenta-se como ingrediente em potencial para substituir os mais tradicionais. Entretanto, um fato a ser considerado na utilização de seus grãos na alimentação animal é o elevado teor em taninos em alguns cultivares.

Os taninos são constituídos por compostos fenólicos com massa molecular entre 500 e $3000 \mathrm{Da}$, que ocorrem naturalmente em vegetais e possuem a capacidade de combinarem-se com proteínas e outros polímeros.

A presença de taninos nos alimentos tem alguns efeitos detrimentais na saúde e no desenvolvimento animal, incluindo depressão na palatabilidade do alimento, na ingestão voluntária, na digestibilidade das proteínas, dos carboidratos, do amido e de lipídios e diminuição na absorção do cálcio (CHANG et al, 1994). Mas, a presença de tanino também apresenta efeitos benéficos, como redução no nível de lipídio corporal e do colesterol sanguíneo em várias espécies animal (CHUNG et al, 1998).

O sorgo possui quantidades consideráveis de tanino, sendo que este se encontra principalmente na testa do grão e o teor de tanino varia de 1,3 a 3,6\% para os cultivares com alto teor e de 0,1 a 0,7\% para os cultivares de baixo teor (MYER et al, 1986) ou sem tanino (SCHEUERMANN, 2003).

A utilização de sorgo com alto teor em tanino na dieta de frangos de corte é desvantajosa por diminuir o ganho de peso e piorar a conversão alimentar, além de reduzir o consumo, quando comparado ao milho e ao sorgo de baixo teor de tanino (ROSTAGNO et al, 1973; OLIVETTI; RAPACCINI, 1987; IBRAIHM et al. 1988). Porém, pesquisando a adição de sorgo com alto e baixo tanino e do ácido tânico em rações para frangos de corte, Pinto et al. (2002), verificaram que a inclusão de sorgo e ácido tânico à ração melhorou o desempenho produtivo das aves.

Silva et al (2002), estudando o efeito da adição de sorgo e de ácido tânico em rações para frangos de corte sobre a deposição de gordura corporal e de colesterol plasmático, verificaram que as aves alimentadas com ração contendo sorgo com baixo 
teor de tanino e baixo nível de ácido tânico tiveram uma menor deposição de gordura abdominal e visceral.

Um outro fator relacionado ao tanino é a sua interferência sobre o pâncreas de frangos de corte (AHMED et al, 1991). Os autores observaram aumento de duas vezes no tamanho do órgão, que foi atribuído ao aumento na produção de enzimas digestivas tais como tripsina e $\alpha$-amilase, as quais são inibidas pelo tanino. Resultados obtidos por Nyachoti; Atkinson (1995), entretanto, mostraram não haver hipertrofia pancreática em resposta ao tanino do sorgo.

Dessa forma, o presente trabalho teve como objetivo avaliar o efeito do sorgo baixo teor em tanino sobre o desempenho produtivo, o rendimento de carcaça e cortes comerciais e, a deposição lipídica corporal de frangos de corte.

\section{MATERIAL E MÉTODOS}

O experimento foi conduzido no Aviário Experimental da Faculdade de Ciências Agrárias e Veterinárias, FCAV/UNESP - Jaboticabal (SP). Foram utilizados 510 pintos machos de um dia de idade da linhagem Cobb, os quais foram criados até os 42 dias em galpão convencional subdividido em boxes. As rações experimentais (isoenergéticas e isoprotéicas) foram elaboradas com milho, farelo de soja e sorgo com baixo tanino, cultivar Saara desenvolvido pela EMBRAPA, em substituição ao milho nos níveis 0, $25,50,75$ e $100 \%$ constituindo os 5 tratamentos.

As rações foram fornecidas ad libitum durante todo o período experimental, sendo uma inicial (1 a 21 dias), com $23 \%$ de PB e $2900 \mathrm{kcal} / \mathrm{Kg}$ de EM, e uma de crescimento (22 a 42 dias), com $20 \%$ de PB e $3200 \mathrm{kcal} / \mathrm{kg}$ de EM, conforme as tabelas de composição de ingredientes e exigências nutricionais propostas por Rostagno et al (2005).

Para a determinação do desempenho produtivo das aves, estas foram pesadas no início e no término do experimento, para a obtenção do ganho de peso; o consumo de ração foi determinado por diferença entre a quantidade oferecida nas parcelas e as sobras nos comedouros e, a conversão alimentar foi obtida pelo quociente do consumo de ração e ganho de peso das aves.

Aos 42 dias de idade, 10 aves de cada tratamento foram pesadas individualmente, sacrificadas por deslocamento cervical e sangradas pela veia jugular. 
Procedeu-se em seguida a retirada das penas e vísceras para a avaliação do rendimento de carcaça e dos cortes comerciais. Para análise de proteína (A.O.A.C., 1995) e de lipídios, foram utilizadas outras 10 aves, que após o sacrifício, foram congeladas e posteriormente moídas.

O tecido adiposo abdominal foi removido e pesado de acordo com as recomendações de Kubena et al (1974). Este tecido adiposo se refere àquele superposto às bordas adjacentes e descendentes do duodeno e limitado ventralmente pelo esterno e parede muscular abdominal (NICKEL et al, 1977).

A determinação dos índices de gordura da moela, gordura abdominal e hepatossomático decorreram imediatamente após o sacrifício das aves. A moela, o fígado e o tecido adiposo abdominal foram removidos e pesados para cálculo dos índices hepatossomáticos pela relação peso do fígado/peso corporal x 100, a gordura abdominal pelo peso da gordura abdominal/peso corporal x 100 e da gordura da moela pelo peso da moela/peso corporal x 100 .

Os lipídios totais da carcaça, músculo e fígado foram determinados gravimetricamente após extração com clorofórmio-metanol $\left(2: 1, \mathrm{v}_{\mathrm{v}} \mathrm{v}^{-1}\right)$, como descrito por Bligh; Dyer, (1959).

O colesterol total plasmático foi quantificado pelo método proposto por Alain et al (1974), por meio de "kit" (Cat.60, LABTEST Diagnóstica S.A., Belo Horizonte, $\mathrm{MG})$.

As aves foram distribuídas nos boxes em um delineamento inteiramente casualizado com 5 tratamentos e 3 repetições, totalizando 15 parcelas com 34 frangos cada. Para a análise estatística dos resultados obtidos foi utilizado o procedimento GLM do SAS (Statistical Analysis System, 1995). Para se verificar a significância entre as médias dos tratamentos foi utilizado o teste de Tukey, ao nível de 5 e $1 \%$ de probabilidade.

\section{RESULTADOS E DISCUSSÃO}

Os valores médios para consumo de ração, ganho de peso e conversão alimentar durante os períodos experimentais ( 1 a 21 e 1 a 42 dias) encontram-se na Tabela 1. Verificou-se que os tratamentos utilizados não influenciaram no desempenho produtivo das aves. Entretanto, as aves alimentadas com a ração controle (T1) apresentaram o menor consumo de ração e a melhor conversão alimentar durante todo o período 
experimental. Entre os tratamentos contendo sorgo, as aves que receberam ração com total substituição do milho (T5) apresentaram tendência para melhores ganho de peso e para conversão alimentar, a qual foi seguida pelo tratamento com $25 \%$ de substituição do milho pelo sorgo (T2), no período de 1 a 42 dias. De maneira geral, os resultados obtidos para desempenho produtivo utilizando-se o sorgo, foram satisfatórios, os quais são concordantes com os obtidos por Queiroz et al (1978), quando substituíram o milho da ração de frangos de corte por quantidades crescentes $(0,50,75$ e $100 \%)$ de sorgo com baixo conteúdo em tanino. Verificaram que o ganho de peso das aves não foi afetado quando o milho foi substituído por até $100 \%$, porém, a conversão alimentar das aves que receberam ração à base de milho foi melhor que a das alimentadas com sorgo, sendo a pior conversão observada ao nível de $50 \%$ de substituição do milho por sorgo.

Tabela 1. Valores médios obtidos para consumo de ração, ganho de peso e conversão alimentar de frangos de corte alimentados com as diferentes rações durante os períodos experimentais

\begin{tabular}{cccc}
\hline Tratamentos & $\begin{array}{c}\text { Consumo de } \\
\text { Ração }(\mathbf{g})\end{array}$ & $\begin{array}{c}\text { Ganho de } \\
\text { Peso }(\mathbf{g})\end{array}$ & $\begin{array}{c}\text { Conversão } \\
\text { Alimentar }(\mathbf{g})\end{array}$ \\
\hline T1 & 1 a 21 dias & & \\
T2 & 981 & 544 & 1,80 \\
T3 & 1133 & 579 & 1,96 \\
T4 & 1121 & 542 & 2,08 \\
T5 & 1164 & 554 & 2,10 \\
DMS & 1122 & 541 & 2,07 \\
CV(\%) & 0,20 & 0,07 & 0,51 \\
& 6,57 & 4,97 & 9,56 \\
\hline T1 & & $\mathbf{1 ~ a ~ 4 2 ~ d i a s ~}$ & $1,60^{\mathrm{A}}$ \\
T2 & 3467 & 2169 & $1,69^{\mathrm{AB}}$ \\
T3 & 3707 & 2192 & $1,77^{\mathrm{B}}$ \\
T4 & 3749 & 2123 & $1,76^{\mathrm{B}}$ \\
T5 & 3812 & 2165 & $1,68^{\mathrm{AB}}$ \\
\hline DMS & 3708 & 2209 & 0,14 \\
CV(\%) & 0,36 & 0,16 & 3,17 \\
\hline & 3,66 & 2,71 & \\
\hline
\end{tabular}

T1- ração controle, T2- substituição de $25 \%$ do milho por sorgo, T3- substituição de 50\% do milho por sorgo, T4- substituição de $75 \%$ do milho por sorgo, T5- substituição de $100 \%$ do milho por sorgo 
Os resultados obtidos assemelham-se também aos encontrados por Sanford (1963) e Bornstein; Bartov (1967). Sanford (1963), não verificou diferença significativa no consumo alimentar de frangos de corte ao utilizar grãos de sorgo comparativamente ao milho como fonte energética na composição das rações. Bornstein; Bartov (1967), não observaram diferenças no desempenho produtivo quando substituíram em $100 \%$ o milho pelo sorgo, nas rações para frangos de corte.

Rostagno et al (1973); Elkin et al (1978); Rodrigues (1996), concluíram que o ganho de peso e a conversão alimentar foram melhores para as aves alimentadas com sorgo de baixo teor em taninos, em comparação às alimentadas com sorgo de alto tanino.

Albino et al (1982), concluíram que a substituição total do milho pelo sorgo não traz prejuízos no desempenho produtivo de frangos de corte, exceto pelas mudanças na pigmentação da pele das aves quando se utiliza níveis acima de $60 \%$ em substituição ao milho. Observações visuais também demonstraram, no presente trabalho, mudanças na pigmentação da pele das aves a partir dos 28 dias de idade com $50 \%$ de substituição do milho pelo sorgo. No entanto, esta situação pode ser amenizada com a utilização de sorgo com endosperma amarelo (ROSTAGNO, 1986) ou suplementação de xantofila nas rações (GUALTIERI; RAPACCINI, 1990; FIALHO; BARBOSA, 1992) quando se deseja frango com pele mais amarelada.

A menor qualidade protéica do sorgo em relação ao milho, em termos de aminoácidos metionina e lisina foi relatada por Scheuermann (2003). A possibilidade de complexação dos taninos com aminoácidos, proteínas, carboidratos e minerais, e inibição da atividade de enzimas digestivas (WARREHAM et al, 1994) também pode estar associada à diminuição da qualidade nutricional das dietas contendo sorgo. A formação de complexo de baixa digestibilidade dos taninos com os nutrientes da dieta, antes da inibição direta das enzimas digestivas foi demonstrado por Butler; Rogler (1992). Diante desta possibilidade, pode-se inferir que, neste estudo, a ausência do milho na ração ( $100 \%$ de substituição) parece ter dificultado a complexação dos taninos com os nutrientes dietários, o que pode torná-los mais disponíveis, resultando em tendência para melhor ganho de peso e conversão alimentar para as aves. A avaliação da atividade das enzimas digestivas poderá colaborar para elucidar as tendências observadas, a qual se constitui na continuidade desta pesquisa.

Os resultados para rendimento de carcaça e dos cortes comerciais estão apresentados na Tabela 2. O rendimento de carcaça das aves não foi influenciado pelos diferentes tratamentos durante o período experimental. Verificou-se que não houve 
influência dos diferentes tratamentos sobre o rendimento de carcaças e cortes comerciais, indicando que o sorgo apresenta potencial na atividade avícola.

Tabela 2. Valores médios obtidos para porcentagens de rendimento de carcaça e dos cortes comerciais e para a proteína total na carcaça de frangos de corte alimentados com diferentes rações aos 42 dias de idade

\begin{tabular}{ccccccc}
\hline Tratamento & Carcaça & Peito & Coxa & Asa & Dorso & $\begin{array}{c}\text { Proteína } \\
\text { Carcaça }\end{array}$ \\
\hline T1 & 65,96 & 31,59 & 35,33 & 12,10 & 20,98 & $19,65^{\mathrm{A}}$ \\
T2 & 64,91 & 31,26 & 35,75 & 12,70 & 20,30 & $18,65^{\mathrm{AB}}$ \\
T3 & 64,90 & 31,80 & 34,97 & 12,31 & 20,92 & $18,41^{\mathrm{AB}}$ \\
T4 & 64,77 & 31,52 & 35,58 & 12,27 & 20,63 & $18,18^{\mathrm{B}}$ \\
T5 & 65,25 & 32,42 & 34,96 & 12,21 & 20,41 & $18,75^{\mathrm{A}}$ \\
\hline DMS & 2,12 & 1,56 & 1,57 & 0,72 & 1,31 & 1,44 \\
CV & 2,58 & 3,81 & 3,50 & 4,57 & 4,97 & 6,02 \\
\hline
\end{tabular}

Média de 10 aves por tratamento.

Médias seguidas de letras iguais, na coluna, não diferem entre si pelo Teste de Tukey ( $p>0,05)$.

T1- ração controle, T2- substituição de $25 \%$ do milho por sorgo, T3- substituição de 50\% do milho por sorgo, T4- substituição de $75 \%$ do milho por sorgo, T5- substituição de 100\% do milho por sorgo

A menor porcentagem de proteína foi obtida para as carcaças das aves alimentadas com ração com $75 \%$ de substituição em relação à dieta controle $(\mathrm{p}<0,05)$. Entre as rações contendo sorgo houve maior deposição protéica na carcaça das aves alimentadas com $100 \%$ de substituição, seguidas das aves que receberam dieta contendo 25 e $50 \%$ de substituição do milho pelo sorgo.

Os resultados obtidos neste experimento são concordantes com os obtidos por Seki-Dias et al (2001); Pinto et al (2002), que também não observaram prejuízos quanto ao rendimento de carcaça e cortes comerciais bem como deposição protéica na carcaça de aves alimentadas com ração contendo altos níveis de ácido tânico.

Os valores médios para os índices de gordura abdominal e da moela, índice hepatossomático e para os pesos médios relativos do pâncreas e da moela estão apresentados na Tabela 3. Observou-se diferenças significativas $(\mathrm{p} \leq 0,05)$ somente para os valores relativos à moela. Assim, os níveis de substituição do milho pelo sorgo não influenciaram nas quantidades de gordura abdominal, no peso relativo do fígado e do pâncreas. 
Tabela 3. Valores médios para índice gordura abdominal (IGA), índice gordura da moela (IGM), índice hepatossomático (IHS), pesos relativos do pâncreas (PRP) e da moela (PRM), das aves alimentadas com rações experimentais aos 42 dias de idade.

\begin{tabular}{cccccc}
\hline Tratamentos & IGA & IGM & IHS & PRP & PRM \\
\hline T1 & 1,03 & $0,51^{\mathrm{A}}$ & 1,59 & 0,18 & $1,49^{\mathrm{A}}$ \\
T2 & 1,01 & $0,49^{\mathrm{A}}$ & 1,69 & 0,18 & $1,45^{\mathrm{A}}$ \\
T3 & 1,12 & $0,49^{\mathrm{A}}$ & 1,60 & 0,17 & $1,39^{\mathrm{AB}}$ \\
T4 & 0,98 & $0,34^{\mathrm{C}}$ & 1,62 & 0,18 & $1,21^{\mathrm{B}}$ \\
T5 & 1,06 & $0,39^{\mathrm{BC}}$ & 1,53 & 0,16 & $1,24^{\mathrm{B}}$ \\
\hline DMS & 0,20 & 0,09 & 0,24 & 0,03 & 0,21 \\
CV & 15,17 & 16,93 & 12,00 & 11,91 & 12,14 \\
\hline
\end{tabular}

Médias seguidas de letras iguais, na coluna, não diferem entre si pelo Teste de Tukey (p>0,05).

T1- ração controle, T2- substituição de $25 \%$ do milho por sorgo, T3- substituição de $50 \%$ do milho por sorgo, T4substituição de $75 \%$ do milho por sorgo, T5- substituição de $100 \%$ do milho por sorgo

Os resultados obtidos são semelhantes aos de Nyachoti et al (1996) que não observaram alterações significativas no peso relativo do pâncreas das aves alimentadas com ração contendo sorgo. No entanto, são discordantes dos encontrados por El Zubeir; Mustafa (1992), que relataram que com a inclusão de sorgo em total substituição ao milho nas dietas para frangos de corte, resultou em um aumento na deposição de gordura abdominal. Estes mesmos autores ainda observaram que a substituição total do milho pelo sorgo acarretou em maior peso relativo do fígado e quando substituíram apenas $25 \%$ do milho pelo sorgo encontraram um menor peso relativo deste órgão mesmo comparado à dieta controle (milho e soja).

O aumento na deposição de gordura abdominal em aves em função da ingestão de taninos também foi observada por Poor-Reza; Edriss (1997), atribuindo aos efeitos do tanino sobre a digestibilidade da proteína, e a conseqüente redução na disponibilidade de aminoácidos.

O índice de gordura da moela e o peso relativo desse órgão foram menores para as aves alimentadas com ração contendo 75 e $100 \%$ de substituição do milho pelo sorgo, respectivamente. Porém, com base nas literaturas nacional e internacional consultadas, não foi encontrada uma explicação mais aprofundada de como o sorgo atua nesse órgão e na deposição de gordura neste em aves.

A Tabela 4 apresenta os resultados médios da porcentagem de lipídios totais na carcaça, no músculo ( peito ) e no fígado das aves nos diferentes tratamentos, além da concentração de colesterol total plasmático. Observou-se que os tratamentos 
não apresentaram efeitos significativos sobre a porcentagem de lipídios na carcaça, músculo e fígado, porém, a concentração de colesterol total plasmático foi maior para as aves submetidas aos tratamentos $25,50,100,0$ e $75 \%$ de substituição do milho pelo sorgo, respectivamente.

Tabela 4. Porcentagens totais de lipídios na carcaça, no músculo (peito) e no fígado, e colesterol total plasmático das aves alimentadas com as diferentes rações experimentais aos 42 dias de idade.

\begin{tabular}{ccccc}
\hline Tratamentos & Carcaça(\%) & Músculo $(\%)$ & Fígado $(\%)$ & $\begin{array}{c}\text { Colesterol total } \\
(\mathbf{m g} / \mathbf{d L})\end{array}$ \\
\hline T1 & 12,21 & 1,99 & 3,99 & $97,64^{\mathrm{BC}}$ \\
T2 & 12,85 & 1,68 & 3,72 & $119,34^{\mathrm{A}}$ \\
T3 & 12,47 & 1,80 & 3,65 & $111,61^{\mathrm{AB}}$ \\
T4 & 11,99 & 2,09 & 3,76 & $95,88^{\mathrm{C}}$ \\
T5 & 13,48 & 2,18 & 3,96 & $98,27^{\mathrm{BC}}$ \\
\hline DMS & 2,25 & 0,62 & 0,55 & 14,09 \\
CV & 11,02 & 25,08 & 11,27 & 10,61
\end{tabular}

Médias seguidas de letras iguais, na coluna, não diferem entre si pelo Teste de Tukey (p>0,005).

T1- ração controle, T2- substituição de $25 \%$ do milho por sorgo, T3- substituição de $50 \%$ do milho por sorgo, T4- substituição de $75 \%$ do milho por sorgo, T5- substituição de $100 \%$ do milho por sorgo

De acordo com Sgarbieri (1987), o acúmulo de lipídios no fígado pode ser consequência de diminuição de síntese de lipoproteínas plasmáticas, o que estaria associado a fatores lipotrópicos. Os processos metabólicos que utilizam grupos metílicos em grandes quantidades ou dietas pobres em metionina tendem a aumentar os lipídios hepáticos.

Quanto à concentração de colesterol total plasmático, verificou-se que houve diferença estatística $(p>0,05)$ entre os tratamentos, sendo que o nível mais elevado foi para o tratamento T2 (25\% de substituição do milho pelo sorgo) e em relação ao tratamento T4 (75\% de substituição) seguido pelos tratamentos controle (T1) e T5 (substituição total).

A redução dos níveis de colesterol plasmático em ratos hipercolesterolêmicos e normocolesterolêmicos alimentados com dieta com alto e baixo colesterol suplementado com ácido tânico foi observada por Yugarani et al (1993); por Forsythe (1995). Chang et al (2001) concluíram, que compostos fenólicos são agentes hipocolesterolêmicos.

A influência do tanino na concentração do colesterol total plasmático pode estar relacionada à inibição da 3-hidroxi-3-metilglutaril-CoA redutase, enzima limitante na 
biossíntese do colesterol, pois catalisa a redução de HMG-CoA pelo NADPH para formar mevalonato, ponto de maior controle na colesterogênese (BOUCHER et al, 1998).

Através dos resultados obtidos e da semelhança nutricional do sorgo ao milho, torna-se promissora a inclusão deste cereal em rações para frangos de corte, ainda mais pelo fato do mesmo não ser tradicionalmente utilizado na alimentação da população brasileira. Considerando-se ainda o fato deste grão ser em média $20 \%$ mais barato que o milho, e que a alimentação representa cerca de $60 \%$ dos custos da produção de frangos de corte, o sorgo torna-se uma alternativa para ampliar a produção de carne de frango, sem, contudo, aumentar demasiadamente os custos do produto final.

\section{CONCLUSÃO}

Nas condições em que o experimento foi realizado, pode-se concluir que:

- O sorgo baixo teor em tanino substitui totalmente o milho nas rações para frango de corte, sem prejuízos significativos para o desempenho produtivo.

- A substituição parcial ou total do milho pelo sorgo não interfere no rendimento de carcaça das aves.

- A inclusão do sorgo baixo teor em tanino nas rações não influencia a deposição lipídica abdominal das aves.

- A substituição de $75 \%$ do milho pelo sorgo proporciona menor concentração de colesterol total plasmático.

\section{REFERÊNCIAS}

AHMED, A.E.; SMITHARD, R. et al. Activities of enzymes of the pancreas, and the lumen and mucosa of the small intestine in growing broiler cockerels fed tannincontaining diets. British Journal Nutritive, v. 65, p. 189-97, 1991.

ALAIN, C.A. et al. Clinical Chemistral. v. 20, p.470,1974.

ALBINO, L.F.T.; NERY, J.R. et al. Substituição do milho pelo sorgo em rações para frangos de corte. Revista Sociedade Brasileira de Zootecnia, v. 11, n. 4, p. 706-20, 1982. 
ASSOCIATION OF OFFICIAL ANALYTICAL CHEMISTS. Official Methods of Analysis. 16 ed. Washington: AOAC, 1995. Vol. II.

BLIGH, E.J.; DYER, N.J. A rapid method of total lipid extraction and purification. Cannadian Journal Biochemestry Physiologic, v. 37, p.911-7, 1959.

BORNSTEIN, S.; BARTOV, I. Comparisons of sorghum grain (milo) and maize as the principal cereal grain source in poultry rations. I. Their relative feeding value for broilers, British Poultry Science, v. 8, p. 213-21, 1967.

BOUCHER, P.; LORGERIL, M, et al. Effect of dietary cholesterol on low density lipoprotein-receptor, 3-hydroxi-3-methylglutaryl-CoA reductase, and low density lipoprotein receptor-related protein mRNA expression in healthy humans. Lipids, v. 33, n. 12, p. 1177-86, 1998.

BUTLER, L.G.; ROGLER, J.C. Biochemical mechanisms of the antinutritional effects of tannins. In: Phenolic compounds in food and theis effects on health.I. HO, C.T., LEE, C.Y., AND HUANG, M. -T. (Ed.), American Chemical Society (ACS Symposium Series 506), v. 23, p. 298-301, 1992.

CHANG, J.J.; CHEN, T.H. et al. The in vitro inhibitory effect of tannin derivatives on 3-hydroxy-3-methylglutaryl-coenzyme A reductase on Vero cells. Pharmacology, v. 62 , p. 224-28, 2001.

CHANG, M.J.; BAILEY, J.W. et al. Dietary tannins from cowpeas and tea transiently alter apparent calcium absorption and utilization of protein in rats. Journal Nutrition, v. 124, p. 283-88, 1994.

CHUNG, K.; WONG, T.Y. et al. tannins and human health: a review. Critical Reviews in Food Science and Nutrition, v. 38, p. 421-64, 1998.

EL ZUBIER, E.A.; MUSTAFA, E.A. The replacement value of sorghum gluten meal for soya-bean meal in broiler chick diets. Animal Feed Science and Technology, v. 36, p. $339-42,1992$.

ELKIN, R.S.; FEATHERSTON, W.R. et al. Investigations of leg abnormalities in chickes consuming high tanin sorghum grain diets. Poultry Science, p. 757-62, 1978.

FIALHO, E.T.; BARBOSA, H.P. Utilização do sorgo em rações para suínos e aves. Sete Lagoas - MG, 1992. (Circular Técnica, n. 16)

FORSYTHE, W.A. Soy protein, thyroid regulation and cholesterol metabolism. Journal Nutrition, v. 125, p. 619S-23S, 1995.

GUALTIERI, M.; RAPACCINI, S. Sorghum grain on poultry feeding. World Poultry Science Journal. v.46, p.246-51, 1990.

IBRAIHM, S.; FICHER, C. et al. Improvement of the nutritional quality of Egyptian and Sudanese sorghum grains by the addition of phosphates. British Poultry Science, v. 29, p. 721-28, 1988. 
KUBENA, L.F. Factores influencing the quantity of abdominal fat in broilers. 3 dietary energy levels. Poultry Science, v.53, p.974-78, 1974.

MYER, R.O.; GOBERT, D.W. et al. Nutritive value of high and low-tannin grain sorghums harvested and stored in the high-moinsture state for growing finishing swine. Journal Animal Science, v. 62, p. 1290-97, 1986.

NICKEL, R.; SCHUMER, A. et al. Anatomy of the domestic birds. Verlag, p.47, 1977.

NYACHOTI, C.M..; ATKINSON, J.L. The effect of feeding high-tannin sorghum on digestive organ response and overall performance of broiler chicks. Poultry Science (Supplement 1), v. 74, p. 125 (abstract), 1995.

NYACHOTI, C.M.; ATKINSON, J.L.et al. Response of broiler chicks fed a high tannin sorghum diet. Journal of Applied Poultry Research, v. 5, p. 239-45, 1996.

OLIVETTI, A; RAPACCINI, S. Utilizzazione dei sorghi a basso tenore in tannini nell’alimentazione dei polli da carne. Atti della Società Italiana di Scienze Veterinarie, v. XLI, p. 783-86, 1987.

PINTO, M.M.; CARVALHO, M.R.B. et al. Uso do sorgo com alto e baixo teor em taninos na alimentação de frangos de corte. In: CONGRESSO DE INICIAÇÃO CIENTÍFICA, PRESIDENTE PRUDENTE, Resumo... 2002.

POUR-REZA, J.; EDRISS, M.A. Effects of dietary sorghum of different tannin concentrations and tallow suplementation on the performance of broiler chicks. British Poultry Science, v.38, p.512-17, 1997.

QUEIROZ, A.C.; ROSTAGNO, H.S. et al. Sorgos com diferentes conteúdos em tanino como substitutos do milho para aves. Revista Ceres, v. 25, p. 234-41, 1978.

RODRIGUES, W.A. Tanino em sorgo: Métodos de determinação e análise genética. 1996. 81p. Tese (Doutorado). Escola Superior de Agricultura Luiz de Queiroz. Universidade de São Paulo. Piracicaba.

ROSTAGNO, H.S. Utilização do sorgo nas rações de aves e suínos. Informativo Agropecuário. v. 12, p.18-27, 1986.

ROSTAGNO, H. S.; FEATHERSTON, W.R. et al. Studies on the nutritional value of sorghum grains with varying contents for chicks. Poultry Science. v. 52, p. 765-72, 1973.

ROSTAGNO, H.S.; ALBINO, L.F.T. et al. Tabelas brasileiras para aves e suínos: Composição de alimentos e exigências nutricionais de aves e suínos. 2 ed. Viçosa: UFV, 2005, 186p.

SANFORD, P.E. Sorghum grain as a source of energy for poultry. Poultry Science. v. 42, p. 1303-04, 1963. 
SCHEUERMANN, G.N. Utilização do sorgo em rações para frangos de corte. UBAInforma. p. 95-96, 2003. (Informativo Técnico - União Brasileira de Avicultura)

SEKI-DIAS, L.T; CARVALHO, M.R.B. et al. Efeito do ácido tânico e do sorgo no desempenho produtivo e deposição de gordura na carcaça de frangos de corte (Gallus domesticus). In: SIMPÓSIO LATINO AMERICANO DE CIÊNCIAS DE ALIMENTOS, 4.Anais... Campinas, p. 205, 2001.

SGARBIERI, V.C. Alimentação e Nutrição: Fator de saúde e desenvolvimento. Campinas: Editora da UNICAMP, 1987, 387p.

SILVA, J.D.T.; CARVALHO, M.R.B. et al. Efeito do sorgo e do ácido tânico na deposição de gordura visceral e abdominal em frangos de corte. In: Congresso de Iniciação Científica, Presidente Prudente, resumo, 2002.

STATISTICAL ANALYSIS SYSTEMS INSTITUTE. User's guide. Version 6, 4.ed. Cary: SAS®/STAT, SAS Institute Inc., 1995. 365p.

WARREHAM, C.N.; WISEMAN, J. et al. Processing and antinutritive factors in feedstuffs. In: COLE, D.J.A., VARLEY, M.A. Principles of pig sciences. Nottingham, 1994, 427p.

YUGARANI, T.; TAN, B.K. et al. The effects of tannic acid on serum and liver lipids of RAIF and RICO rats feed on high fat diets. Biochemistry and Physiology. v.104A, n.2, p. 339-43, 1993. 
